\title{
Removal of 2-chlorophenol Using Rice Husk Activated Carbon Prepared by $\mathrm{ZnCl}_{2} / \mathrm{H}_{3} \mathrm{PO}_{4}$ Activation
}

\author{
ALLWAR ALLWAR* and SYAMSURIZAL \\ Department of Chemistry, Faculty Mathematics and Natural Sciences \\ Islamic University of Indonesia, Yogyakarta, 55584, Indonesia. \\ *Corresponding author E-mail: allwar@uii.ac.id
}

http://dx.doi.org/10.13005/ojc/330531

(Received: July 05, 2017; Accepted: August 20, 2017)

\begin{abstract}
The rice husk, agricultural solid waste was successfully converted into activated carbon using mixture of chemical agents $\mathrm{ZnCl}_{2} / \mathrm{H}_{3} \mathrm{PO}_{4}$. Their properties including porous structures, surface functional groups and morphology structures were carefully studied. Applications of rice husk activated carbons were applied for removal of 2-chlorophenol in aqueous solution under different conditions. The nitrogen isotherm exhibits Type IV, and the presence of hysteresis loop clearly shows the predominantly mesoporous characteristics. The BET and Langmuir surface areas are 144.6 and $212.5 \mathrm{~m}^{2} \mathrm{~g}^{-1}$, respectively. The equilibrium adsorptions for both Langmuir and Freundlich isotherms show the best a regression coefficient closed to unity. The values of correlation coefficient $\mathrm{R}^{2}=0.9976$ represented the satisfactory pseudo-second-order model. The results show that rice husk activated carbon was effectively used as adsorbent for removal of 2-chlorophenol.
\end{abstract}

Keywords: Rice husk, Activated carbon, 2-chlorophenol, $\mathrm{ZnCl}_{2} / \mathrm{H}_{3} \mathrm{PO}_{4}$.

\section{INTRODUCTION}

Activated carbon is a solid material with relatively small particle sizes: powder or granular form having excellent characteristics as adsorbent. The characteristics can be separated in physical and chemical properties and make them suitable for application in many catalytic processes. Activated carbon is highly porous structures and sufficiently surface functional group while its activity is studied in the adsorption process involving as adsorbent, catalyst and catalyst support in chemical reaction. It is capable to absorb a wide variety of pollutants including organic pollutant, dyes and heavy metals ${ }^{1}$. Porous structures of adsorbent must be excellent characteristics including high surface area, pore volume and pore size distribution. These properties are essentially performance indicators as adsorbent for removal of contaminant from aqueous solution. The highly porous structures have a strong interaction between adsorbate molecules and active site of carbon. Graphene structures of activated carbon contain with electron-rich-regions and surface functional groups with play important roles for determination of removal of pollutant. Two assumptions of mechanism can be describe that the $\pi$ electron on the graphene layers may interact with $\pi-\pi$ electrons of adsorbate, and basic surface 
functional groups such as carbonyl on surface may bond the aromatic ring of phenolic compound through donor acceptor interaction ${ }^{2,3}$.

2-chlorophenol as a phenolic organic aromatic compound can be obtained as water pollutants and deliberated as major toxic pollutants event in low concentration as low as $0.1 \mathrm{ppm}$. This chemical is used as intermediate process in the synthesis of resin, plastics, dye, pesticides, insecticide and many others ${ }^{4,5}$. The polluted waste drains into natural water, canal, river, etc. representing a serious problem and affecting not only human life but also flora and fauna as well 6,7 . In the last few years, a great attention had been focused on the detection and removal of 2-chlorophenol and phenolic derivatives due to uncontrolled discharging of industries effluents and drinking water disinfection. Various treatment technologies are used for removal of the pollutants before discharging into the water body including adsorption, ion-exchange, chemical reaction, reverse osmosis, electrodialysis and filtration ${ }^{8-10}$.

Previous works have been reported that activated carbon can be obtained from various raw materials possessing highly carbonaceous compounds such as coconut shell, kernel, bamboo, rice husk, tire, etc. Rice husk is an agricultural solid waste from farmer which is easily obtained around milling process and inexpensive material. The compositions of rice husk have been studied and being investigated for preparation of activated carbon as adsorbent for removal of organic pollutants. Improving the quality of porous structures and adsorption capacity has been intensively studied.Development of technologies for preparation of high porous activated carbon is very important to obtained maximum process in removal of contaminates ${ }^{11-13}$.

In the present work, activated carbon was prepared from waste of rice husk and used as an adsorbent for removal of 2-chlorophenol. Preparation activated carbon was carried out with hydrothermal method using mixture chemical agents $\mathrm{ZnCl}_{2} / \mathrm{H}_{3} \mathrm{PO}_{4}$. Characteristics of activated carbon were applied by Surface Area analyzers Quanthachrome, FT-IR spectroscopy and SEMEDX. Adsorption capacity was determined at various parameters including: $\mathrm{pH}$, contact times, concentration and adsorbent dosage. The amount of 2-chlorophenol uptakes was evaluated by UV Visible Spectrophotometerat wavelength of $274 \mathrm{~nm}$. Adsorption isotherms data were used for studying the Langmuir and Freundlich adsorption isotherm including kinetic models.

\section{MATERIALS AND METHODS}

\section{Materials}

Rice husk can be easily obtained at open area around milling process or rice field. It was washed thoroughly with distilled water to remove impurities attacked on the rice husk and dried in an oven at $120^{\circ} \mathrm{C}$ overnight. The chemicals involving zinc chloride $\left(\mathrm{ZnCl}_{2}\right)$, phosphorous acid $\left(\mathrm{H}_{3} \mathrm{PO}_{4}\right)$, buffer solution, 2-chlorophenol are obtained from E Merck and used without further purification.

\section{Preparation of Rice Husk Activated Carbon}

About $200 \mathrm{~g}$ of rice husk activated carbon was prepared by pyrolysis proses at constant temperature $200^{\circ} \mathrm{C}$ for 2 hours. After cooling down, the $150 \mathrm{~g}$ of biochar of rice husk was poured into $300 \mathrm{ml}$ of $\mathrm{ZnCl} 2 / \mathrm{H}_{3} \mathrm{PO}_{4}$ solution obtained from mixtures $10 \% \mathrm{ZnCl}_{2}$ and $10 \% \mathrm{H}_{3} \mathrm{PO}_{4}$. The Mixture was refluxed at $80^{\circ} \mathrm{C}$ for 24 hours. Therefore, it was filtered and washed with distilled water for few times and neutralized until its $\mathrm{pH} 6-7$. The dried sample was taken into close reactor and pyrolyzed in graphite furnace at $300^{\circ} \mathrm{C}$ for $2 \mathrm{~h}$. as a contact time. The dried production was rice husk activated carbon and kept in desiccators for further analysis.

\section{Procedures of Adsorption of 2-chlorophenol}

To study the advance adsorption process for 2-chlorophenol removal, some different parameters were applied during adsorption process including $\mathrm{pH}(\mathrm{pH}=4,5,7,8)$, adsorbent dosage $(0.5,1.0,1.5,2.0 \mathrm{~g})$, contact times $(15,30,45,60$ $\mathrm{min}$ ) and initial 2-chlorophenol concentration (50, 100, 150, $200 \mathrm{mg} / \mathrm{L})$. The amount of 2-chlorophenol removal was calculated using UV-Vis spectrophotometer at wavelength of $274 \mathrm{~nm}$. Equilibrium adsorption isotherm was evaluated using Langmuir and Freundlich adsorption isotherm including itskinetic process ${ }^{14}$. The amount of 2-chlorophenol removed by the rice husk 
activated carbon was studied using batch technique in a shaker at room temperature. The adsorption capacity $\left(q_{e}\right)$ and the removal \% (R, \%) were evaluated using the following equation (1):

$\mathrm{qe}=($ co-ce $) \mathrm{v}$

$$
\mathrm{R}, \%=\frac{\mathrm{m}}{(\mathrm{co}-\mathrm{ce}) 100}
$$

Where, Co and Ce are the initial and the equilibrium concentrations $(\mathrm{mg} / \mathrm{L}$ ) of phenol and 2-chlorophenol. The $\mathrm{V}$ is volume of the solution $(\mathrm{L})$ and $\mathrm{m}$ is the mass of adsorbent $(\mathrm{gr})^{15}$.

\section{RESULTS AND DISCUSSION}

\section{Surface area analysis}

Textural characteristics of activated carbon were carried out based on the nitrogen adsorption and desorption isotherms at $77 \mathrm{~K}$. Fig. 1 shows the shape of nitrogen isothermal exhibited IV isotherms corresponding to the great development of mesoporous structures based on the IUPAC classification: micropores (8 to $100 \AA$ ), mesopores $(100-500 \AA)$ and macropores $(>500 \AA)^{15,16}$. The presence of hysteresis loop at P/Po $>0.4$ were clearly from multilayer condensation of physisorption associated with the filling and emptying of mesopores. Surface areas were evaluated at different relative pressure in which BET (Brunauer-Emmett-Teller) and Langmuir methods range from $\mathrm{P} / \mathrm{Po} 0.05$ to 3.0 , and $\mathrm{P} / \mathrm{Po}<$ 0.05 , respectively. The results show that BET surface area is $144.6 \mathrm{~m}^{2} \mathrm{~g}^{-1}$ corresponding with the multilayer, and Langmuir surface area is 212.5 $\mathrm{m}^{2} \mathrm{~g}^{-1}$ corresponding with monolayer. Fig. 2 shows the $\mathrm{BJH}$ shape for the distribution of radius pores started from 16 to $200 \AA$. From the data presented in the Fig. 2, it can be seen that the rice husk activated carbon produced the predominantly mesoporous structures. Previous work reported that preparation of activated carbon using chemical activation with $\mathrm{ZnCl}_{2}$ have produced activated carbon with microporous characteristics, while with
$\mathrm{H}_{3} \mathrm{PO}_{4}$ resulted mesoporous structure. Therefore, due to the effect of combination of $\mathrm{ZnCl}_{2}$ and $\mathrm{H}_{3} \mathrm{PO} 4$, the pores have shifted from microporousto mesoporous structures. The textural characteristics of rice husk activated carbon can be concluded that it was posted in Table 1.

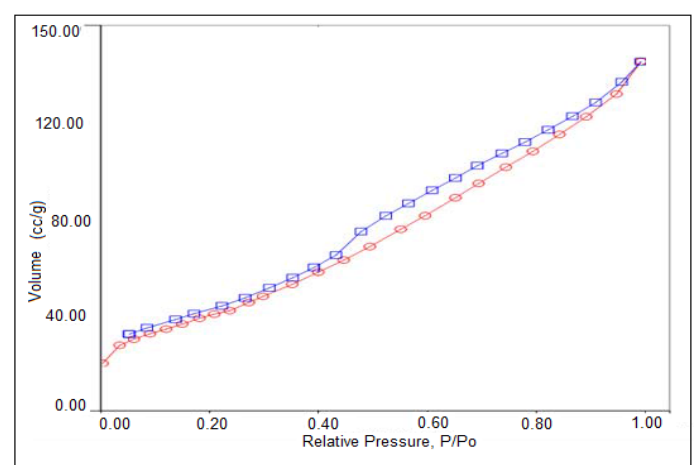

Fig.1. Nitrogen adsorption desorption isotherm of rice husk activated carbon.

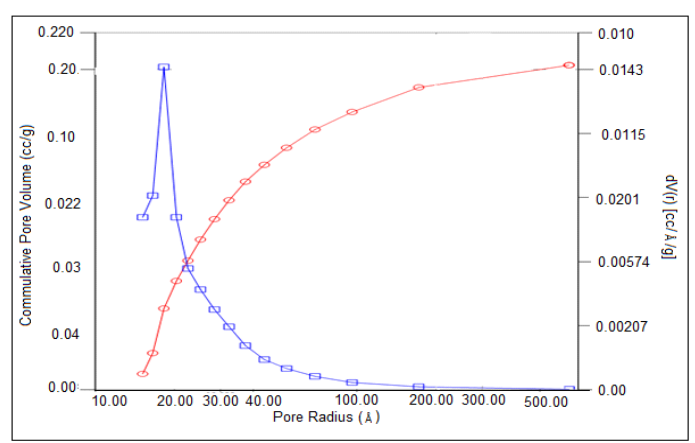

Fig.2. BJH shape of pore size distribution of rice husk activated carbon.

\section{Functional groups of activated carbon}

Investigation of the functional groups attached on the surface of activated carbon was carried out by FTIR. Fig. 3A shows FTIR spectra of biochar of rice husk that was obtained from pyrolysis process at $200^{\circ} \mathrm{C}$. Fig. 3B shows FTIR spectra of rice husk activated carbon that was prepared by the mixtures of chemical agents $\mathrm{ZnCl}_{2} / \mathrm{H}_{3} \mathrm{PO}_{4}$. The effect of chemical agents on rice husk activated carbon has created new spectra assumed to have

Table. 1: Textural characteristic of rice husk activated carbon.

\begin{tabular}{lccccc}
\hline $\begin{array}{l}\text { Langmuir surface } \\
\text { area }\left(\mathbf{m}^{2} \mathbf{g}^{-1}\right)\end{array}$ & $\begin{array}{c}\text { BET surface } \\
\text { area }\left(\mathbf{m}^{2} \mathbf{g}^{-1}\right)\end{array}$ & $\begin{array}{c}\text { DR Micropore } \\
\text { volume }\left(\mathbf{c c g}^{-1}\right)\end{array}$ & $\begin{array}{c}\text { BJH Pore } \\
\text { volume}\left(\mathbf{c c g}^{-1}\right)\end{array}$ & $\begin{array}{c}\text { DA Pore } \\
\text { radius }(\AA)\end{array}$ & $\begin{array}{l}\text { BJH Pore } \\
\text { radius }(\AA)\end{array}$ \\
\hline 212.5 & 144.6 & 0.064 & $0.2 \mathrm{ccg}^{-1}$ & 8.8 & 18.3 \\
\hline
\end{tabular}


new surface functional groups. A wide transmittance band at maximum at $3427.58 \mathrm{~cm}^{-1}$ is assigned as $\mathrm{O}-\mathrm{H}$ stretching vibration of hydroxyl group as a result of modification phosphoric acid. A band at $1633.04 \mathrm{~cm}^{-1}$ is generally attributed to $\mathrm{C}=\mathrm{O}$ stretching vibration in carboxyl groups ketones, aldehydes or lactones and it is also associated to $\mathrm{C}=\mathrm{C}$ stretching vibration in aromatic rings. A weak band at $1382.32 \mathrm{~cm}^{-1}$ is attributed to $\mathrm{C}-\mathrm{H}$ asymmetries bending. A medium band 1097 and $1068.02 \mathrm{~cm}^{-1}$ are ascribed to $\mathrm{C}-\mathrm{O}$ stretching vibration in ester and ionized linkage $\mathrm{P}-\mathrm{O}$ in acid phosphorous ester. These bands are also due to the Si-O-Si asymmetric stretching vibration ${ }^{18}$. The presence of band at $796.05 \mathrm{~cm}^{-1}$ and 793.17 are ascribed to $\mathrm{C}-\mathrm{H}$ in out-of-plane bending in the edges of aromatic rings and $\mathrm{Si}-\mathrm{OH}$ stretching vibration. The band at 464.57 is assigned to $\mathrm{Si}-\mathrm{O}$ group. This functional group indicates that rice husk activated carbon contain silicate elements ${ }^{19}$.

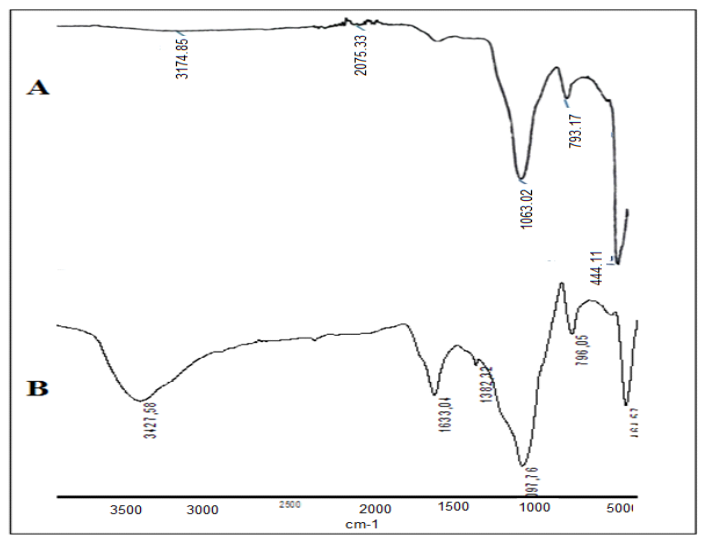

Fig. 3. (A) FTIR spectra of rice husk activated carbon without chemical agent (B) FTIR spectra of rice huisk activated carbon with $\mathrm{ZnCl}_{2} / \mathrm{H}_{3} \mathrm{PO}_{4}$

\section{Surface Morphology of rice Husk Activated carbon}

Figure. 4 shows the morphology structure and elemental analysis of rice husk activated carbon. The image shows irregular external surface with cracks and crevices into various size of pores. It seems that the forming of cavities of rice husk activated carbon was resulted from the initiation and evaporation process of chemical agent during the pyrolysis process. However, the silicate and zinc are not easily removed in this process which was assumed due to the low temperature. The surface of particles is most likely covered with silicate which is supported with the highest silicate content. The elemental analysis of rice husk activated carbon was determined by EDX measurement. The relative composition is $22.2 \%$ of silicon, $58.1 \%$ of oxygen, $5.5 \%$ of chlorine, $9.2 \%$ of carbon and $5.2 \%$ of zinc. This result is relevance with the FTIR data consisting of the Si-O functional group.

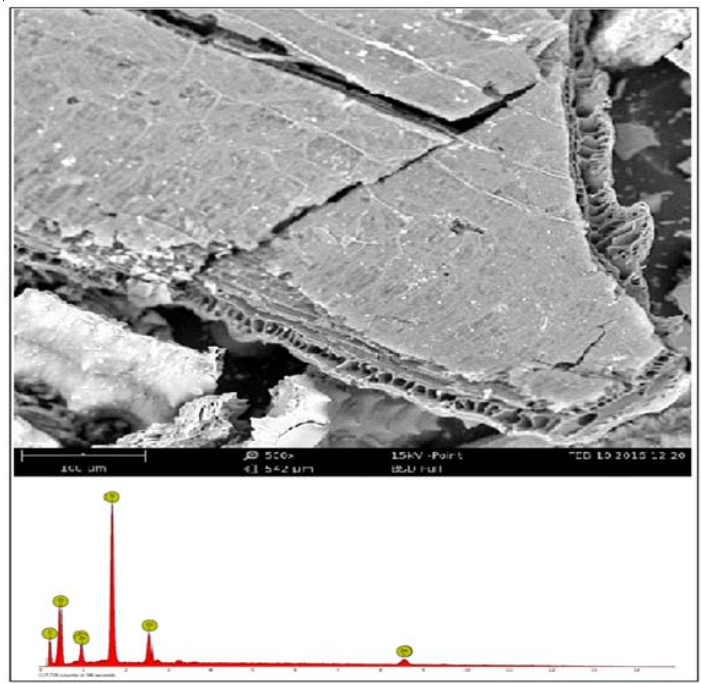

Fig. 4. Surface morphology and elemental analysis of rice husk activated carbon.

Application of rice husk activated carbon on the Adsorption process

\section{Effect of adsorbent dosage}

Figure. 5 shows the effect of adsorbent dosage on percentage of 2-cholorophenol removal at $\mathrm{pH} 7$ and room temperature. The shape of adsorption capacity increases with increasing the adsorbent dosage. This phenomenon is due to the fact that as the adsorbent dosage increases, the number of sorption sites of adsorbent such as pore volume and surface area are available for 2 chlorophenol adsorption.

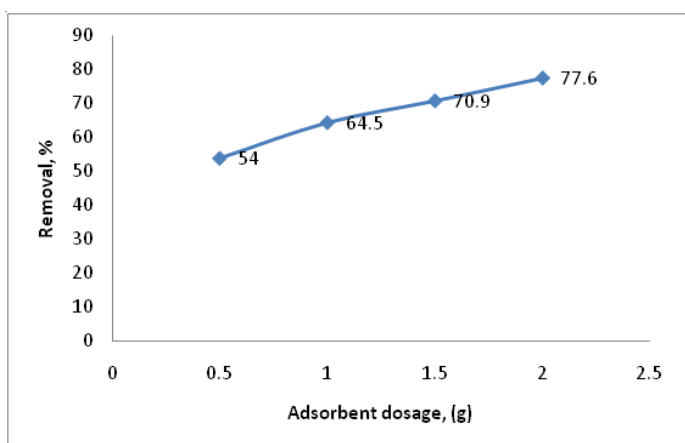

Fig. 5. Adsorption of 2-chlorophenol on rice husk activated carbon against adsorbent dosage. 


\section{Effect of $\mathrm{pH}$}

Figure. 6 shows that the effect of $\mathrm{pH}$ can influence the adsorption capacity of 2-chlorophenol. It was observed that the percentage of removal of 2-chlorphenol increased as $\mathrm{pH}$ solution increased. The 2-chlorophenol uptake sharply increases at $\mathrm{pH} 4$ to 5 , remains constant from 5 to 7 and decreases at $\mathrm{pH}$ 8. The maximum sorption was obtained at $\mathrm{pH} 7$. The adsorption process of 2-chlorophenol could be explained by two methods: chemisorption and physisorption. At lower $\mathrm{pH}, 2$-chlorophenol solution had acid condition with the excess positive charges, $\mathrm{H}^{+}$ions on the surface of activated carbon while the rice husk activated carbon have active site with negative charges. Interaction and repulsion between positive and negative charges caused a neutralization ions and result the increasing of the removal of 2-cholorophenol. At higher $\mathrm{pH} 8$, surface of adsorbent has high the negative charges. The excess negative charges in the solution resulted repulsion between 2-chlorophenol and adsorbent which caused reducing of 2-chlorophenol removal.

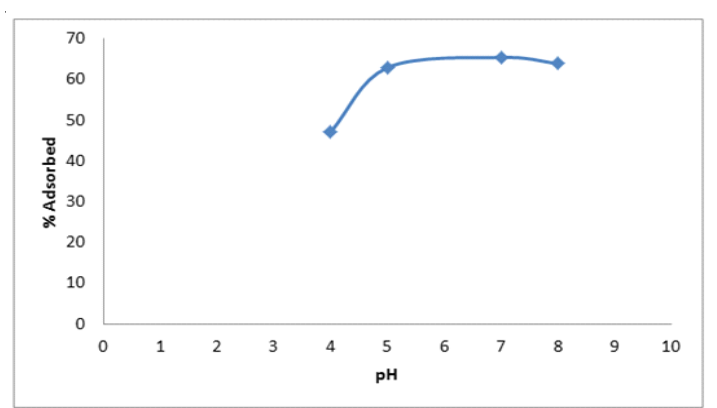

Fig. 6. Adsorption of 2-chlorophenol on rice husk activated carbon against $\mathrm{pH}$.

\section{Effect of contact times}

The effect of contact times is one of the important roles to determine the adsorption capacity. The possible reasons are its effect on the chemical reaction that occurs between adsorbate and surface area of adsorbent. Fig. 7 shows the relationship between contact time and the percentage adsorption from solution with rice husk activated carbon. The removal of 2-chlorophenol have trend to increase as contact time increase reaching to a maximum value at $45 \mathrm{~min}$. and decrease after $45 \mathrm{~min}$. The increasing adsorption capacity was due to the fact that increasing contact time enhanced the diffusion or transportation adsorbate to the pores starting from external to the internal site of the adsorbent. The increasing contact time to $60 \mathrm{~min}$. Show the decreasing of the adsorption of 2-chlorophenol. It is assumed that the reduction of adsorption capacity was caused by the fulfill of adsorbate into pores during adsorption process.

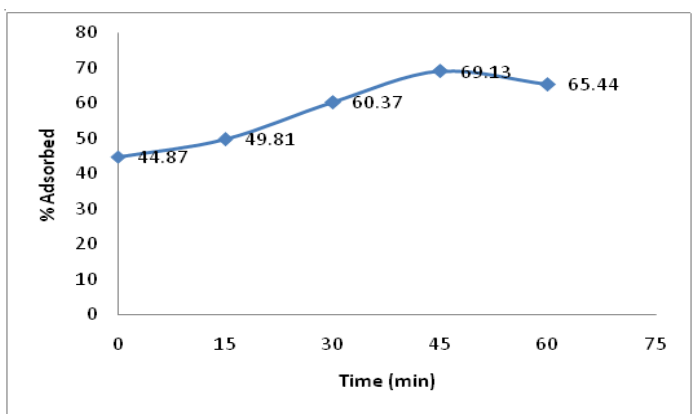

Fig. 7. Adsorption of 2-chlorophenol on rice husk activated carbon against contact time.

\section{Adsorption isotherms}

The equilibrium adsorption is usually described by the amount of adsorbate on the adsorbent using models of the Langmuir and Freundlich isotherms. Once the surface site is filled, no further sorption can take place at that site. This phenomenon indicates that the surface chemistry of the adsorbent reaches a saturation point where the maximum adsorption of the surface was achieved.

The Langmuir isotherm model was carried out using the following equation:

$\frac{c_{e}}{q_{e}}=\frac{1}{q_{m} k_{L}}+\frac{c_{e}}{q_{m}}$

Where $\mathrm{C}_{\mathrm{e}}$ is the concentration of adsorbate at equilibrium in solute $(\mathrm{mg} / \mathrm{L}), \mathrm{q}_{\mathrm{e}}$ is the adsorption capacity at equilibrium solute concentration (mg/ $\mathrm{g}), \mathrm{q}_{\mathrm{m}}$ is the maximum adsorption capacity relating to monolayer coverage $(\mathrm{mg} / \mathrm{g}), \mathrm{K}_{\mathrm{L}}$ is the Langmuir constant related to affinity of point of $(\mathrm{L} / \mathrm{mg})$.

Figure. 8 shows the linear plot $\left(R^{2} 0.9784\right)$ of specific adsorption (Ce/qe) versus equilibrium concentration $(\mathrm{Ce})$ indicated the results the Langmuir model.

The Freundlich isotherm model follows the equation based on the multilayer of adsorbent. The Freundlich equation is expressed as following equation: 


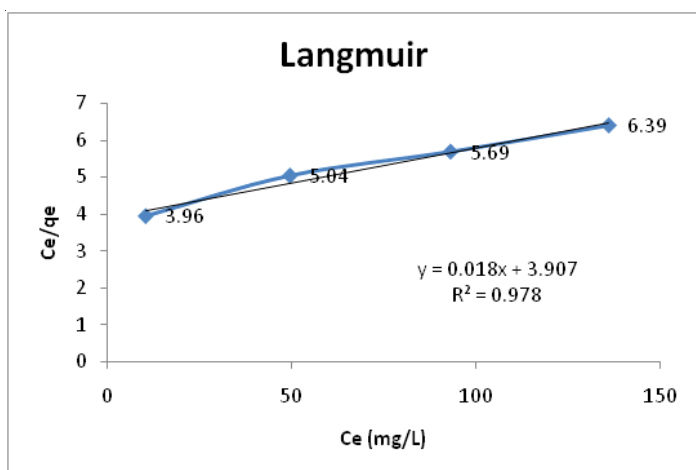

Fig 8. Shape of adsorption isotherm model of 2chlorophenol.

The linear plot of the Freundlich isotherm model is given as the following equaltion.

Where $\mathrm{K}_{\mathrm{F}}$ is the Freundlich constant related to several environmental factors, $n$ is the parameter presenting the energy heterogeneity of the adsorption sites. Fig. 9 shows a plot linier of log qe versus log Ce shows the theFeundlich isotherm for adsorption. The values of $\mathrm{K}_{\mathrm{F}}$ and $\mathrm{n}$ are obtained from both intercept and slope, respectively. The parameter $n$ is usually follow the value range at $1<\mathrm{n}<10$ relating to the favorable adsorption process. The Langmuir and Freudlich isotherms were plotted in Table 2.

Table 2 illustrates the Langmuir and Freundlich isotherm models for the adsorption of 2-chlorophenol. Based on the experimental data, both Langmuir and Freundlich isotherm model show best fitting line with $\mathrm{R}^{2}$ values 0.9784 and 0.9838 , respectively. These phenomena indicate that the rice husk activated carbon possess a well adsorption behavior of 2-chlorophenol.

\section{Adsorption Kinetic Modeling}

The adsorption kinetics is important because the kinetics can describe an uptake rate of adsorbate relating to the adsorption mechanism. In this study, the effect of contact time was applied in order to describe the uptake rate of 2-chlorophenol

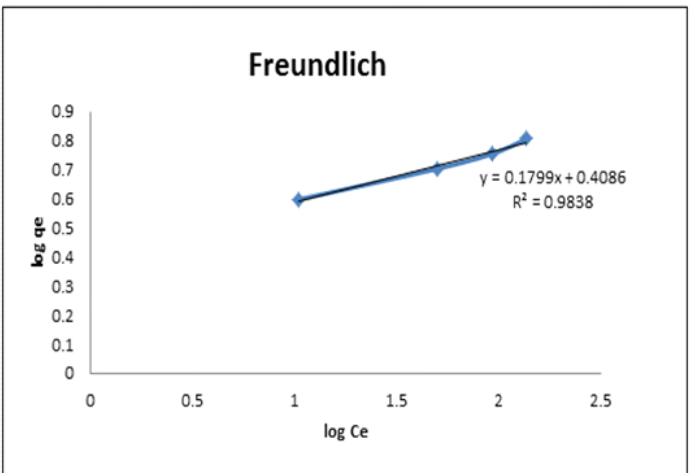

Fig. 9. Shape of adsorption isotherm model of 2chlorophenol.

at different times. To investigate the adsorption kinetics were applied to the model of the pseudofirst-order and pseudo-second-order models. The linear plots of these equations can predict whether the model suitably as an adsorption process or not. The expression for pseudo-first-order equation model is shown in following equation (4):

whereq and $q_{t}$ are the sorption capacities at equilibrium at time $\mathrm{t}$, respectively $(\mathrm{mg} / \mathrm{g}), \mathrm{k}$ is the pseudo-first-order sorption rate constant ( $\mathrm{L} / \mathrm{min}$ ). after integration, from $\mathrm{t}=0$ to $\mathrm{t}=\mathrm{t}$ and $\mathrm{qt}=0$ to $\mathrm{qt}=\mathrm{qt}$ the equation becomes:

The adsorption kinetics of pseudosecond-order models is based on the sorption capacity of the adsorbate. The rate equation is expressed as:

$q_{e}=K_{F} C e^{1 / n}$

$\log q_{e}=\log K_{F}+\frac{1}{n} \operatorname{loq} C e$

$\frac{d q_{t}}{d t}=k\left(q_{e}-q_{t}\right)$

$\log \left(q_{e}-q_{t}\right)=\log q_{e}-\frac{k}{2.303} t$

$\frac{1}{q_{t}}=\frac{1}{k_{2} q_{e}^{2}}+\frac{t}{q_{e}}$

Table. 2 : Langmuir and Freundlich isotherm for 2-chlorophenol adsorbed.

\begin{tabular}{lcccccc}
\hline Adsorbent & \multicolumn{3}{c}{ Langmuir isotherm model } & \multicolumn{3}{c}{ Freundlich isotherm model } \\
& $\mathbf{q}_{\mathbf{m}}(\mathbf{m g} / \mathbf{g})$ & $\mathbf{K}_{\mathbf{L}}(\mathbf{L} / \mathbf{m g})$ & $\mathbf{R}^{\mathbf{2}}$ & $\mathbf{K}_{\mathbf{F}}$ & $\mathbf{n}$ & $\mathbf{R}^{\mathbf{2}}$ \\
\hline $\mathrm{ZnCl}_{2} / \mathrm{H}_{3} \mathrm{PO}_{4}$ & 67,567 & 0,0818 & 0.9784 & 2,5586 & 5,5866 & 0.9838 \\
\hline
\end{tabular}


The adsorption capacity shows as $\mathrm{q}_{\mathrm{e}}$ and $q_{t}(\mathrm{mg} / \mathrm{g})$ are at equilibrium and at time $t$, respectively, $\mathrm{k}_{2}$ is the rate constant of the pseudosecond-order

The experimental data for a plot of log (qe-qt) against time for first order kinetics have poor fitting line with relative low of $R^{2}$ value. The obtained yield shows that the first order kinetics is not appropriate for describing the adsorption kinetics process of 2-chlorophenol by the rice husk activated carbon. The pseudo-second-order rate equation was determined from the slope and intercept of the plot of $t / q t$ versus time (t) which is shown in Fig. 10. In this study, a linear plot found in the experiment data show a best fitting line with high correlation coefficient $R^{2}=0.9976$. It can be noted that the pseudo-second-order model described satisfactorily the adsorption of 2-chlorophenol by the rice husk activated carbon. However, from the

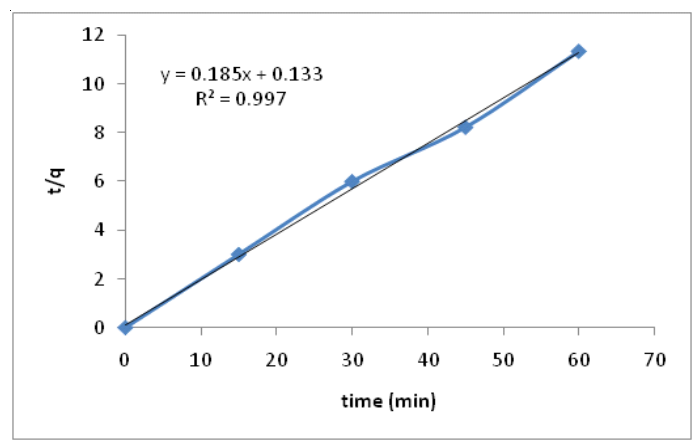

Fig.10 .Shape of the pseudo-second-order kinetics model. calculation for pseudo-first-order equation, the best fitting line with correlation coefficient $R^{2}=0.0449$ indicates that the kinetics of adsorption 2chlorophenol was not satisfied to be described.

\section{CONCLUSIONS}

The preparation of activated carbon from waste of rice husk was successfully investigated. The nitrogen adsorption and desorption isotherm shows Type IV isotherms with predominantly mesoporous structure with multilayer adsorption. BET and Langmuir surface areas were $144.6 \mathrm{~m}^{2} \mathrm{~g}$ 1 and $212.5 \mathrm{~m}^{2} \mathrm{~g}^{-1}$, respectively. The adsorption capacity of 2-chlorophenol was influenced by different parameters. The equilibrium adsorption isotherm can be described by both the Langmuir and the Freundlich isotherms model with best fitting line. The values of $R^{2}$ shows an excellent fitting line for the pseudo-second-order with correlation coefficient $R^{2}=0.9976$ indicating the satisfactory pseudo-second-order model. Finally, rice husk activated carbon was effectively used as adsorbent for removal of 2-chlorophenol.

\section{ACKNOWLEDGEMENTS}

The research was been funded by DPPM and Chemistry Department, Mathematic and Natural Sciences Faculty, Islamic University of Indonesia (UII), Indonesia.

\section{REFERENCES}

1. Yakout, S.M., Sharaf El-Deen, G, Arabian Journal of Chemistry, 2016. $9,155-162$.

2. Haydar, S., Ferro-Garcýa, M.A., RiveraUtrilla, J., Joly, J.P., Carbon, 2003. 41, 387395.

3. Jinping, Z., Wencai, R., Hui-Ming, C, Journal of Materials Chemistry, 2012. 22, 2019720202.

4. Wang, J.P., ; Feng, H. M;Yu, H. Q, .J. Hazard. Mater., 2007. 144, 200-207.

5. Allaboun, H., Abu Al-Rub, F.A, Material, 2016. 9(4), 251.

6. Igbinosa, E.O., Odjadjare, E. E., Chigor, V. N., Igbinosa, I. H., Emoghene, A. O., Ekhaise, F. O., Igiehon, N. O., Idemudia, O. G., Hindawi
Publishing Corporation The ScientificWorld Journal, 2013. 2013.

7. Radhika, M., Palanivelu, K., J. Hazard. Mater., 2006. 138, 116-124.,.

8. Liu, Q.S., Zheng, T., Wang, P., Jiang, J.P., Li, N., Chemical Engineering Journal Hazardous Material, 2010. 157(2-3), 348356.

9. Mohan, D., Singh, K.P., Singh, V.K, Carbon, 2008. 152, 1046-1053.

10. Kumar, S.S., P.; Dhankhar, R. M. V.; Bidra, S., Research Journal of Chemical and Environmental Sciences, 2013. 1(5), 126129.

11. Montes-Morán, M.A., Suárez, D., Menéndez, 
J. A., Fuente, E Carbon, 2004. 42, 12191225.

12. Allwar, IOSR Journal of Applied Chemistry., 2012, 2, 9-15.

13. Kennedy LJ, V.J., Kayalvizhi K, Sekaran G., Chem. Eng. J., 2007, 132, 279-287.

14. Kilic M., A.-V.E., Putin A. E., Journal of Hazardous Materials, 2011, 189, 397- 403.

15. Mouhamed, E.K.S., Ramzi, K., Elimame, E., Younes, M., Arabian Journal of Chemistry, 2014, 7, 109-113.

16. Sing, K.S.W., Everett, D.H., Haul, R.A.W.,
Moscow, L., Pinerotti, R.A., Rouquerol, J., Siemieniewska, T., Pure Appl. Chem, 1985, 57, 603.

17. Dougall, G.J.M., J.S.Afr.Inst.Min.Metall., 1991, 91(4), 109-120.

18. Ghorbani, F., Sanati, A. M., Maleki, M, Environmental Studies of Persian Gulf., 2015, 2(1), 56-65.

19. Abdel Rahim, M.M., Ismail, M. M., Abdel Mageed, A. M. ,International Journal of Advanced Research, 2015, 3(2), p. 491-498. 